Thorax (1954), 9, 46.

\title{
PULMONARY MANIFESTATIONS IN THE DIFFUSE COLLAGEN DISEASES
}

\author{
BY \\ PHILIP ELLMAN AND LEON CUDKOWICZ \\ From the Rheumatism Unit, St. Stephen's Hospital, London, the Plaistow Hospital Chest Unit, London, \\ and the Department of Medicine, Dorking General Hospital
}

(RECEIVED FOR PUBLICATION MAY 28, 1953)

The aetiology of the diffuse systemic collagen diseases, embracing rheumatoid arthritis, scleroderma, dermato-myositis, polyarteritis nodosa, and disseminated lupus erythematosus still remains obscure. The need persists for a wider concept of their clinical picture, with less emphasis on one particular system. Ellman (1947), in respect of rheumatoid arthritis, suggested " rheumatoid disease" as a more comprehensive designation in view of the protean clinical manifestations in certain of the more acute cases.

Among the visceral manifestations of rheumatoid disease attention has already been drawn to the co-existence of joint and lung lesions (Ellman, 1947; Ellman and Ball, 1948; Hart, 1948 ; Schlesinger, 1949 ; Leys and Swift, 1949), which have been regarded as hypersensitivity manifestations in the sense suggested by the work of Rich and Gregory (1943).

Experience of the collagen diseases leads to the recognition of certain distinct clinical patterns, which histopathology fails to differentiate.

Banks (1941), Rich (1946), Spühler and Morandi (1949), Miller (1949), and Kampmeier (1950) emphasized the unity of vascular pathology evident in so wide a variety of clinically dissimilar conditions as disseminated lupus erythematosus, polyarteritis nodosa, dermato-myositis, scleroderma, temporal arteritis, and the rheumatic diseases. This clinical nosology is founded upon the local or generalized manifestations of an apparently uniform and diffuse arteritis. The basic vascular lesion is regarded as a result of fibrinoid degeneration of the ground substance of the arterial wall, leading to progressive occlusion or to aneurysmal dilatation of the vessel wall, with secondary cellular infiltration and ischaemic fibrosis of the dependent structures or organs.

Banks (1941), Klemperer, Pollack, and Baehr (1942), Stokes, Beerman, and Ingraham (1944), and Baehr and Pollack (1947) postulated a unitary concept for the widely differing clinical mani- festations of collagen disease, a view contested, however, by Kellgren (1952).

The similarity of the histopathology of these diseases may indicate a common pathogenesis. The various experimental studies of Bahrmann $\stackrel{\circ}{\longrightarrow}$ (1935), Rich (1942), and Rich and Gregory (1943), in which the injection of histamine or of a foreign of protein induced a necrotizing arteriolitis in the experimental animal, sometimes accompanied by an acute carditis with myocardial Aschoff body formation, suggest that induced vascular hyper- $\bar{\partial}$ sensitivity leads to necrosis of the vascular wall and reactive cellular infiltration. This work lends $\stackrel{\mathbb{Q}}{\complement}$ some support to the unitary theory of the under- $\overrightarrow{\vec{O}}$ lying pathogenesis, but fails to elucidate the iden- $\frac{3}{3}$ tity of the aetiological factors and does not explain the curious specificity of the manifestations in so diverse a group as the clinically separated collagen disorders. The different distribution of the major 으 lesions in these diseases suggests an undue tissue $\underset{x}{x}$ susceptibility, primarily in the structures derived from the mesenchyme or, perhaps, a genetically determined tissue reaction pattern to a common $ᄋ$ aetiological factor. The protean manifestations of the vascular lesions frequently mask the을 diagnosis in the early stages. The clinical find- $\rightarrow$ ings predominating in any one system or organ occasionally bring the patient to various out-N patient departments (Bywaters, 1949) where the true nature of the widespread systemic disease may 0 not at first be apparent. Platt (1949) emphasized ${ }_{\omega}^{N}$ in that respect the difficulty of differentiating be- 0 tween a Type I nephritis and polyarteritis nodosa 50 and Miller (1949) mentioned the frequency of $a \stackrel{\mathbb{\Phi}}{\overparen{D}}$ peripheral neuropathy in polyarteritis nodosa? which introduces its own difficult problems in 0 differential diagnosis.

Pulmonary manifestations in diffuse collagen disorders are not uncommon and changes varying $\frac{\mathbb{\Phi}}{\mathscr{Q}}$ from pleural effusions, partial consolidation, $\bar{O}$ widespread reticulation, miliary mottling to chronic fibrosis and sclero-cystic lung disease haveo 
been described in the rheumatic diseases (Cheadle, 1888 ; von Glahn and Pappenheimer, 1926 ; Masson, Riopelle, and Martin, 1937 ; Hadfield, 1938 ; Gouley, 1938 ; Harkavy, 1941, 1943 ; Rakov and Taylor, 1942 ; Baggenstoss and Rosenberg, 1943 ; Gregory and Rich, 1946 ; Jensen, 1946 ; Klemperer, 1948 ; Ellman, 1947 ; Ellman and Ball, 1948 ; van Wijk, 1948 ; and Lees, 1952) ; in polyarteritis nodosa (Weir, 1939 ; Elkeles, 1944 ; Miller and Daley, 1946 ; and Bergstrand, 1946) ; in disseminated lupus erythematosus (Tumulty and Harvey, 1949); and in scleroderma (Finlay, 1891 ; Kraus, 1924 ; Matsui, 1924 ; Murphy, Krainin, and Gerson, 1941 ; Linenthal and Talkov, 1941 ; Weiss, Stead, Warren, and Bailey, 1943 ; Jackman, 1943 ; Bevans, 1945 ; Getzowa, 1945 ; Goetz, 1945 ; Dostrovsky, 1947 ; Baehr and Pollack, 1947 ; Lloyd and Tonkin, 1948 ; McMichael, 1948 ; Wigley, Edmunds, and Bradley, 1949 ; Church and Ellis, 1950 ; Spain and Thomas, 1950 ; Sante and Wyatt, 1951 ; Hayman and Hunt, 1952).

It is the purpose of this paper to describe the clinical and radiological pattern of some pulmonary manifestations experienced in a variety of

TABLE I

ANALYSIS OF PRESENT SERIES

\begin{tabular}{|c|c|c|c|c|c|c|}
\hline No. & $\begin{array}{l}\text { Init- } \\
\text { ials }\end{array}$ & Age & Sex & $\begin{array}{c}\text { Clinical } \\
\text { Diagnosis }\end{array}$ & $\begin{array}{c}\text { Radiological } \\
\text { Lung } \\
\text { Manifestations }\end{array}$ & $\begin{array}{c}\text { Main } \\
\text { Respiratory } \\
\text { Symptoms }\end{array}$ \\
\hline 1 & A.S. & 36 & $\mathbf{M}$ & Scleroderma & $\begin{array}{l}\text { Fine miliary } \\
\text { mottling }\end{array}$ & $\begin{array}{r}\text { Increasing } \\
\text { dyspnoea }\end{array}$ \\
\hline 2 & B.R. & 66 & $\mathbf{M}$ & Scleroderma & $\begin{array}{c}\text { Enlarged pul- } \\
\text { monary } \\
\text { teries }\end{array}$ & $\begin{array}{c}\text { Increasing } \\
\text { dyspnoea }\end{array}$ \\
\hline 3 & K.R. & 63 & $\mathbf{F}$ & Scleroderma & $\begin{array}{l}\text { Bilateral pleu- } \\
\text { ral fibrosis }\end{array}$ & Dyspnoea \\
\hline 4 & S.W. & 31 & $\mathbf{F}$ & $\begin{array}{l}\text { Dissemina- } \\
\text { ted lupus } \\
\text { erythema- } \\
\text { tosus }\end{array}$ & $\begin{array}{l}\text { Left pleural } \\
\text { effusion; bi- } \\
\text { lateral pleural } \\
\text { fibrosis }\end{array}$ & $\begin{array}{l}\text { Severe dysp- } \\
\text { noea }\end{array}$ \\
\hline 5 & V.A. & 38 & $\mathbf{F}$ & $\begin{array}{l}\text { Dissemina- } \\
\text { ted lupus } \\
\text { erythema- } \\
\text { tosus }\end{array}$ & $\begin{array}{l}\text { Bilateral pleu- } \\
\text { ral fibrosis }\end{array}$ & $\begin{array}{r}\text { Exertional } \\
\text { dyspnoea }\end{array}$ \\
\hline 6 & A.E. & 41 & $\mathbf{F}$ & $\begin{array}{c}\text { Polyarteritis } \\
\text { nodosa }\end{array}$ & $\begin{array}{l}\text { Miliary lung } \\
\text { infiltration } \\
\text { right upper } \\
\text { lobe }\end{array}$ & Attacks of \\
\hline 7 & D.E. & 47 & $\mathbf{F}$ & $\begin{array}{l}\text { Polyarteritis } \\
\text { nodosa }\end{array}$ & $\begin{array}{l}\text { Increased vas- } \\
\text { cular mark- } \\
\text { ings; fine } \\
\text { mottling of } \\
\text { upper zones }\end{array}$ & $\begin{array}{l}\text { Attacks of } \\
\text { " asthma " }\end{array}$ \\
\hline 8 & J.S. & 63 & $\mathbf{M}$ & $\begin{array}{l}\text { Rheumatoid } \\
\text { disease }\end{array}$ & $\begin{array}{l}\text { Left pleural } \\
\text { effusion }\end{array}$ & Dyspnoea \\
\hline 9 & J.D. & 50 & $\mathbf{F}$ & $\begin{array}{c}\text { Rheumatoid } \\
\text { disease }\end{array}$ & $\begin{array}{l}\text { Right basal } \\
\text { opacity }\end{array}$ & $\begin{array}{l}\text { Severe } \\
\text { dyspnoea }\end{array}$ \\
\hline 10 & R.G. & 58 & $\mathbf{F}$ & $\begin{array}{l}\text { Rheumatoid } \\
\text { disease }\end{array}$ & $\begin{array}{l}\text { Basal pleural } \\
\text { fibrosis }\end{array}$ & $\begin{array}{r}\text { Exertional } \\
\text { dyspnoea }\end{array}$ \\
\hline
\end{tabular}

D collagen diseases; to evaluate the response to therapy of the lung changes; and to review these experiences in the light of those recorded in the literature. An attempt has also been made to interpret these lung manifestations in terms of ischaemic changes secondary to pulmonary vascular occlusions.

\section{MATERIAL}

The present 10 cases represent a typical range among a larger series of patients, who have come under the care of one of us (P.E.), falling into the separate groups of the collagen diseases, and in whom the pulmonary features were of major importance.

\section{CLINICAL RESPIRATORY MANIFESTATIONS IN SCLERODERMA}

The significant respiratory symptom in the first three patients was increasing dyspnoea, occurring after the disease as a whole had already been recognized. All showed typical sclerodactylia, telangiectasia, and widespread skin sclerosis by the time they became short of breath. In the first case it was not until the development of skin changes over the thorax in the fourth year of the disease that the effort of breathing became manifest. In the second and third patients dyspnoea was experienced with the development of pleural fibrosis at an even later date. There was no purulent sputum, and there were only a few variable physical signs. With the development of the dyspnoea, chest expansions and vital capacities were found to be reduced. In the first patient the latter fell from 4.2 to 2.6 litres within 18 months. Cyanosis or polycythaemia were not observed and no consistent laboratory findings were seen in respect of alkali reserves or serum electrolytes.

\section{RADIOLOGY}

CASE 1.-The radiographs of the lungs as from the fourth year of the disease showed a progressively increasing peripheral mottling spreading from the bases and hila towards the apices, leaving the latter free. Fine honeycombing was present at the right base.

CASE 2.-In the latter three years of this patient's life the pulmonary arterial markings, particularly in the right lower lobe, became increasingly more prominent (Fig. 1). A tomograph of the pulmonary artery in the right lower lobe suggested early aneurysmal dilatation. The basal pleurae were thickened and adherent to the diaphragms.

CASE 3.- In the sixteenth year of this patient's illness bilateral pleural thickening and increased vascular markings became visible. While receiving treatment with 3-hydroxy-2 phenlycinchoninic acid (H.P.C.). 


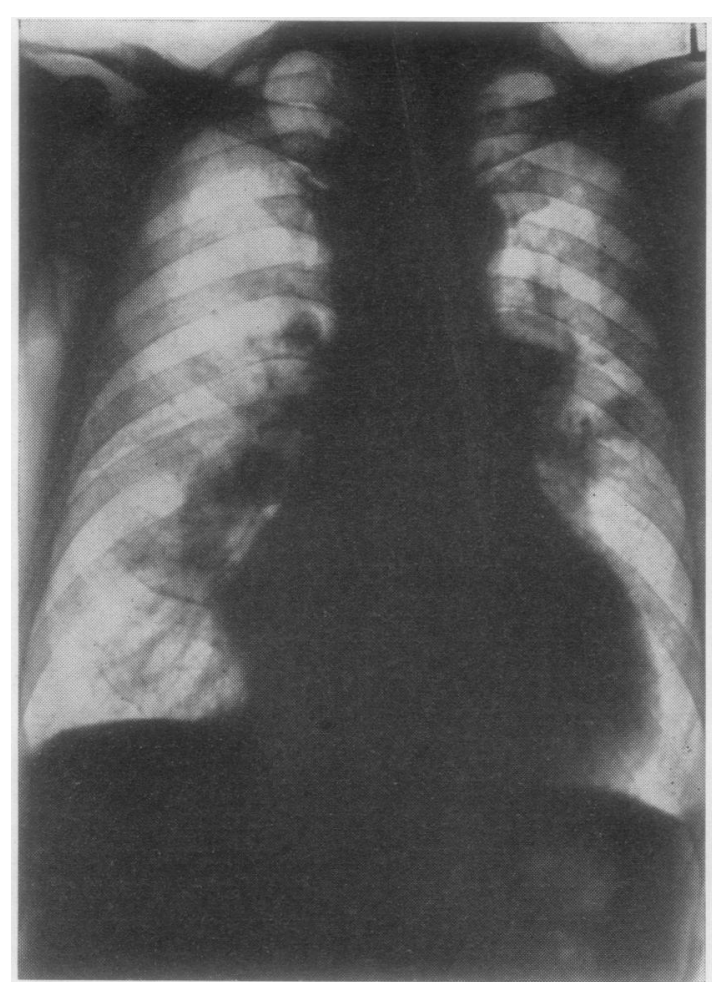

FIG. 1.-Case 2: scleroderma (twentieth year of disease). Radiograph showing cardiac enlargement and prominent pulmonary arteries, particularly the right.

$250 \mathrm{mg}$. thrice daily, the patient developed a right middle lobe abscess and interlobar effusion, which resolved after large doses of penicillin and cessation of H.P.C.

\section{Clinical Responses of Lung Lesions to Treatment}

CASE 1.-An ex-R.A.F. N.C.O., aged 33 years, was admitted under the care of one of us (P.E.) on three separate occasions.

On his first admission in 1950 there was no cardiac enlargement, but a palpable impulse in the pulmonary area was noted.

A course of A.C.T.H., $100 \mathrm{mg}$. daily for 21 days, was given. While there was some evidence, both subjectively and objectively, of a decrease in skin tightness and improved mobility of the fingers, the radiological opacities in the lungs remained unchanged. The vital capacity was not influenced.

On his second admission in 1951 3-hydroxy-2 phenylcinchoninic acid, 1 g. a day, had to be discontinued on the eighteenth day on account of flatulence, anorexia, and later diarrhoea. The clinical response to this substance was inconclusive and the lung changes remained uninfluenced.

A second course of A.C.T.H. had to be abandoned on account of a rapid rise in jugular venous pressure and bilateral basal crepitations, hepatomegaly, a diminished urinary chloride output, and a rapid riş⿸户巳 in serum sodium chloride.

Stopping A.C.T.H. rapidly restored the urinary chloride output, and was followed by a considerab spontaneous diuresis which caused the signs of hypef volemic cardiac failure to subside.

In the interval of one year between the second and third admissions in 1952 considerable cardiac enlargement (Figs. 1 and 3 ) had taken place, suggestive $\vec{\phi}$ both right ventricular hypertrophy with pulmonary hypertension and pericardial involvement. Tke electrocardiogram, the paradoxical venous neck puls and the inspiratory diminution in peripheral pulse volume lend clinical support to the diagnosis of perie cardial constriction.

Bilateral basal crepitations were audible, but the radiograph of the lungs at this stage showed litte change in the fine nodular pattern which had been seen during the previous admission (Fig. 2). A bronchogram was normal.

A course of $100 \mathrm{mg}$. of cortisone daily by mou零 produced no salt-and-water retention, and subjective improvement was noted on the tenth day of the coursfor The thoracic skin was much looser and the vital capæ city increased by 0.8 litres. There were no changes serum electrolyte levels, and the urinary chloride ou甲 put increased slightly. At the end of the course of cortisone occasional crepitations were heard, and the was no change in heart size or lung pattern. The patient remained comparatively unchanged for thre months and was able to enjoy a caravan holiday five weeks.

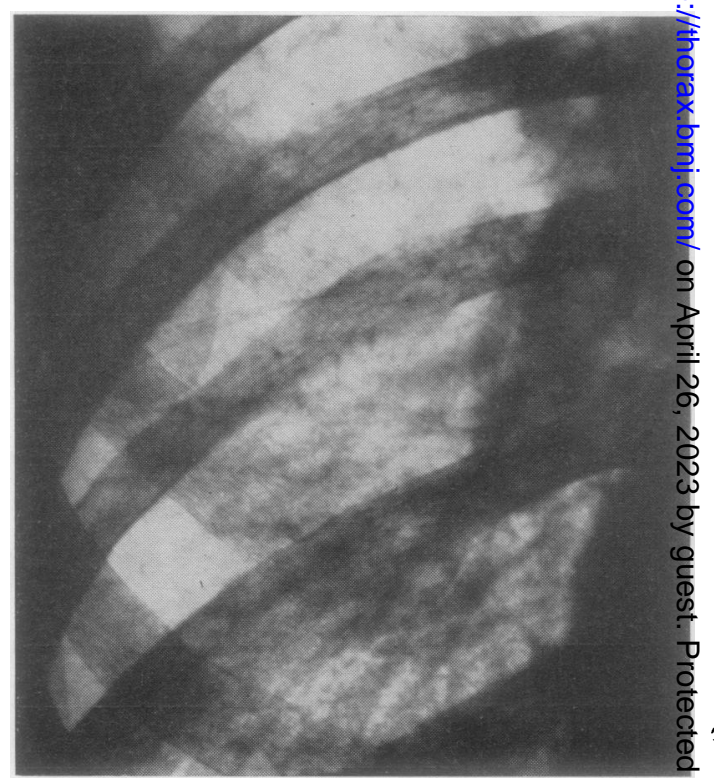

FIG. 2.-Case 1 : scleroderma (fifth year of disease). Lower zona $8 \mathrm{f}$ right lung showing prominent pulmonary artery and fine " honeycombing" at base. 
CASE 2.-A man aged 66 years, whose scleroderma started at the age of 44 , developed exertional dyspnoea in the eighteenth year of his illness, which a year later became aggravated by angina of effort and slight haemoptysis. He manifested obvious sclerodactylia, widespread skin sclerosis, multiple telangiectasia, and some dysphagia for solid food.

The lung fields at this stage showed a very large right pulmonary artery and bilateral pleural fibrosis. In the twentieth year of the disease the above-mentioned symptoms became worse and the heart size increased. The apex beat was in the mid-axillary line. The blood pressure was $220 / 110 \mathrm{~mm}$. Hg. The electrocardiogram suggested a right bundle branch block, and cardioscopy indicated that although there was some right ventricular enlargement most of the increase in size of the heart was due to left ventricular hypertrophy.

Cardiac catheterization was undertaken at Hammersmith Hospital at this stage by Professor J. McMichael. The right auricular pressure was $-2 \mathrm{~mm}$. $\mathrm{Hg}$, and the right ventricular and pulmonary arterial systolic pressure $50 \mathrm{~mm}$. $\mathrm{Hg}$. These pressures were regarded as being compatible with systemic hypertension.

After repeated episodes of congestive heart failure the patient died in the twenty-second year of his illness.

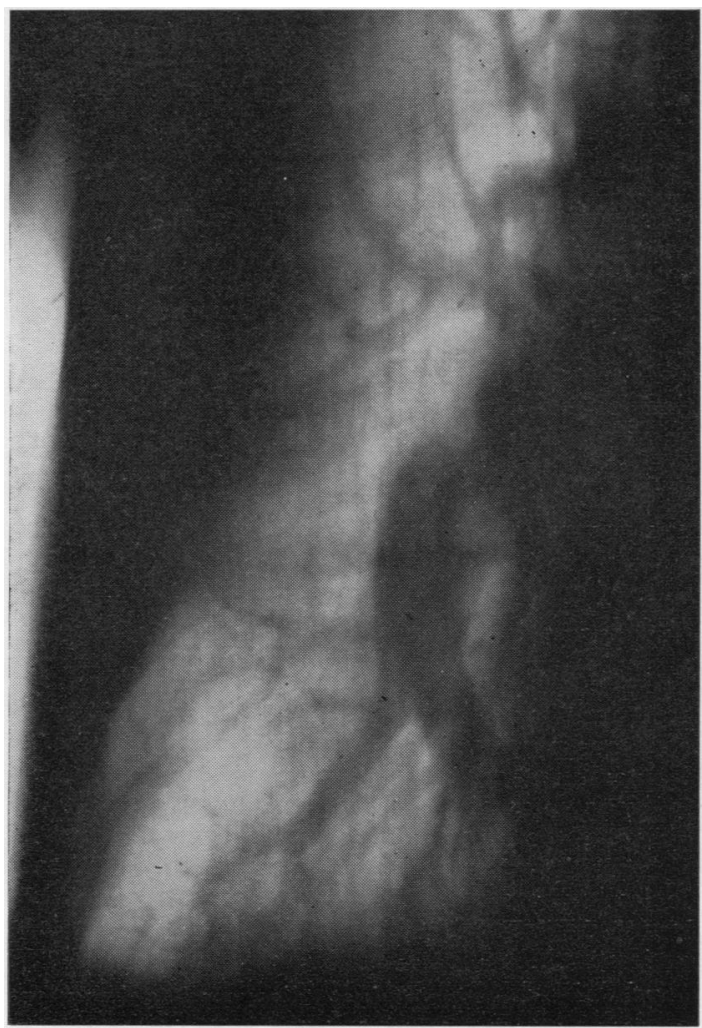

FIG. 3.-Case 2: scleroderma. Tomograph of right lung showing great enlargement of pulmonary artery.
Unfortunately a necropsy could not be obtained. Tomography (Fig. 3) showed that there was aneurysmal dilatation of the right main pulmonary artery.

CASE 3.-K.R., a housewife, aged 63: this patient's lung features, particularly the basal fibrosis, remained uninfluenced by prolonged courses of A.C.T.H. or cortisone. While receiving $750 \mathrm{mg}$. H.P.C. she developed a right middle-lobe abscess, which necessitated high doses of penicillin and cessation of H.P.C. on the thirty-fifth day.

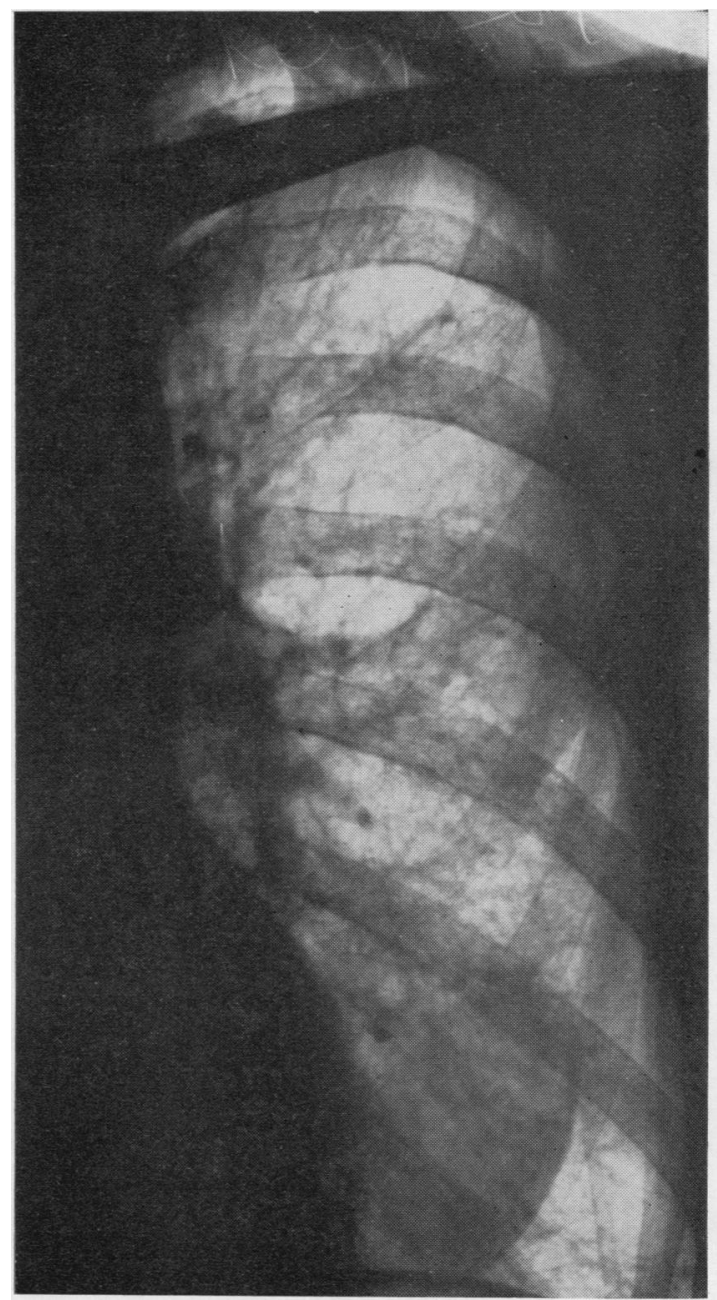

FIG. 4. - Scleroderma : radiograph of the left lung showing increased vascular marking and small cystic areas in midzone.

The patient tolerated H.P.C. very well and showed objective improvement. A gangrenous scab on the right middle finger separated and the skin healed completely, in spite of having been present for two years. 
In addition she had suffered from intractable diarrhoea over the previous 19 months, having as many as 20 stools a day. The frequency of the stools and the hypochromic normocytic anaemia with which this was associated showed no improvement on either A.C.T.H. or cortisone. While on H.P.C. the stools soon became well formed, and on the sixteenth day of the course they were fewer than three a day.

Four months after the course of H.P.C. the patient still had no further diarrhoea, and her stools, two a day, were normal. The lung fields now showed widespread reticulation and areas suggestive of sclerocystic changes (Fig. 4).

\section{RESPIRATORY MANIFESTATIONS IN DISSEMINATED LUPUS ERYTHEMATOSUS}

The three cases falling into this group presented acute pulmonary disease at the inception of their illness.

\section{Clinical Course}

CASE 4.-A typist, aged 31 , was seized by a sudden severe inspiratory pain in the left chest, became rapidly dyspnoeic, and developed a high pyrexia. In addition the left knee became swollen. A period of observation showed the pyrexia to be uninfluenced by chemotherapy, and attempts at thoracentesis were unsuccessful. The diagnosis of pericarditis was made, and a shadow in the region of the left lower lobe, with some elevation and poor excursions of the left diaphragm, suggested either a left lower lobe atelectasis or a pulmonary infarct.

Atelectasis was the more likely, since the shadow had never resolved even 13 years after this episode. The patient has had a series of remissions since then, and while being investigated for recurring knee effusions in 1948, it was thought that the left lower-lobe bronchi were dilated. Her vital capacity is now only 2 litres. She remains dyspnoeic at rest, and the left diaphragmatic excursions are very restricted.

CASE 5.- L.A., a housewife, aged 38, had an acute onset resembling the above. The illness started with a sudden pyrexia of $104^{\circ} \mathrm{F}$., rigors, dyspnoea, and pain in the lower dorsal spine and both sub-costal margins.

The patient appeared cyanosed, and the dyspnoea necessitated nursing in an oxygen tent. Blood cultures remained consistently negative, and the illness was in no way influenced by high doses of sulphonamides or penicillin. A shadow at the right base was regarded as being due to a sub-phrenic abscess, and this was explored surgicaliy on the seventeenth day of the illness, but no pus was found (Fig. 5). In spite of some cyanosis and cough there was no sputum. During the sixth week of the disease the patient was transferred to a chest unit, still extremely ill. Clinical examination of the chest at this stage showed dullness and diminished air entry at both bases. Radiographs showed a diffuse opacity at the right base and mottling in the area of the left lower lobe. On screening it was noted that the left diaphragmatic movements were impaired by an opaque mass undero the left dome. The left subphrenic space was exploredo surgically and again no pus was found. The spleen들 however, was considerably enlarged.

This patient gradually improved without any speci fic therapy (Fig. 6). The acute lung lesions in this case were probably instances of "pneumonitis" as deên scribed by Rakov and Taylor (1942) associated withdisseminated lupus erythematosus or variants of rheumatoid disease (Bywaters, 1949), since the facia erythema of lupus erythematosus appeared threeo months later.

\section{Response of Lung Lesions to Treatment}

An opportunity to observe the response to cor $\overrightarrow{0}$ tisone and A.C.T.H. occurred in Case 4 during arg acute flare-up in the twelfth year of the patient's illness.

CASE 4.-The patient was admitted to St. Stephen Hospital under the care of one of us (P.E.) with a? high swinging fever, tachypnoea, and with swollen $\overrightarrow{0}$ knees. She was very wasted, her face and her breasts s showed erythematous patches and many small telangi= ectases. Her lips and fingers were cyanosed. Theo respiratory movements were almost entirely thoracic Both bases appeared to be dull, and there was noo basal air entry. Rales were present throughout botloै lung fields. With the exception of a tachycardia there were no abnormal findings in the cardiovascula system.

The temperature often reached $104^{\circ} \mathrm{F}$., but blood cultures were sterile. A polymorphonuclear leuco cytosis of 14,000 was present. A course of penicillin? on empirical grounds, and a similar course of sali cylates had no effect on the course of the illness. sternal marrow puncture yielded lupus erythematosu议 cells.

Radiography of the chest at this stage showed eleva tion of the diaphragm, bilateral basal reticulation and apparently a right basal effusion (Fig. 7). Thora centesis, however, produced no fluid.

In view of the grave condition of the patient she was given a course of A.C.T.H. (90-60 mg. per dayt which had to be discontinued on the ninth day is. spite of subjective improvement, because of a purpuri rash with raised blebs over the lumbar spine an $\$$ buttocks. Her temperature rose at once to $103^{\circ}$ Fro and she became very ill and toxic.

It was then decided to try the effect of $100 \mathrm{mg}$. o cortisone per day. Her rash disappeared rapidly. The temperature gradually settled and the patient, afteo bringing up some bloodstained sputum for a few days improved to a very remarkable degree. The lun changes, however, remained both clinically and radiot logically the same. The use of cortisone in this in stance was probably life-saving. but its action is nod understood.

The two patients just discussed subsequentif developed episodes of joint effusions and the typical facial erythema. Exertional dyspnoea . 


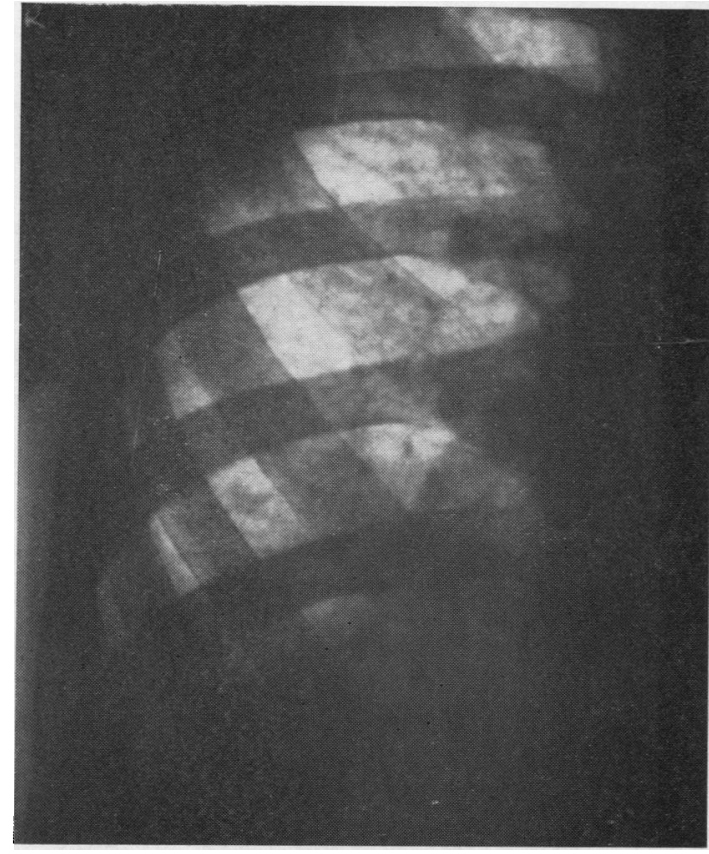

Fig. 5.-Case 5: disseminated lupus erythematosus. Right lung showing para-cardiac shadow

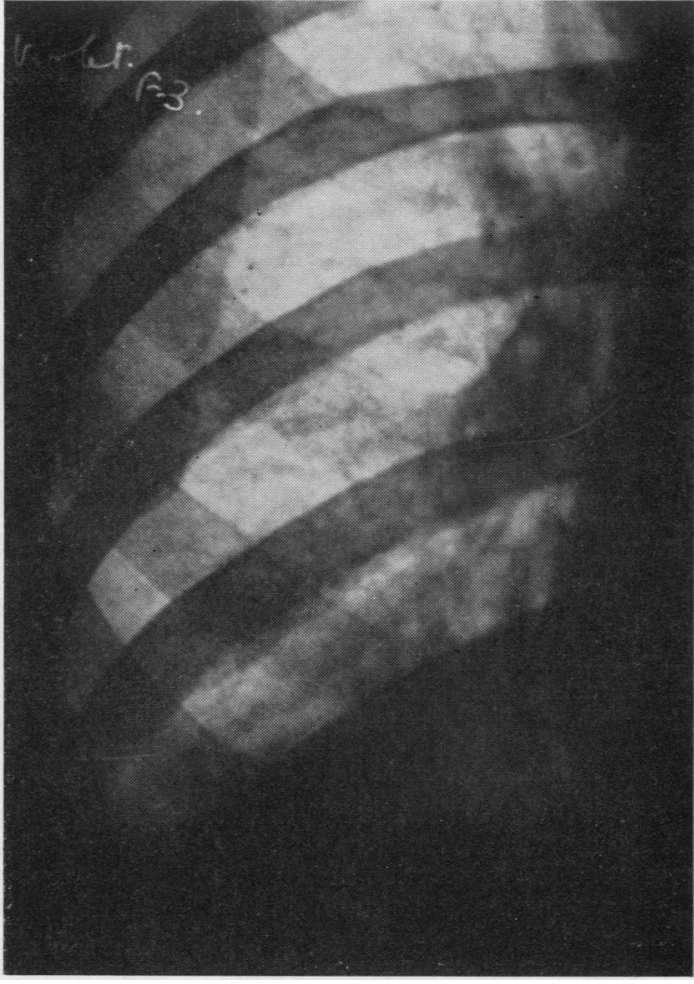

Fig. 6.-Case 5: the same, showing resolution of the right paracardiac shadow. 
their main disability. Radiography in each instance shows marked basal pleural thickening, and diaphragmatic movements, particularly in Case 4, are impaired.

\section{THE RESPIRATORY MANIFESTATIONS OF POLYARTERITIS NODOSA}

The outstanding earliest respiratory symptoms of the seventh and eighth patients were attacks of wheezing and the production of frothy sputum.

\section{Clinical Course}

CASE 6.-A housewife, aged 41, four years after childbirth developed attacks of wheezing, and repeated bouts of diarrhoea, with blood and slime in the stools, occurring more or less simultaneously, began to incapacitate her. This was soon followed by loss of weight, continuous malaise, and mild pyrexia, uninfluenced by sulphonamides. A radiograph at this stage showed a right upper zone miliary pattern (Fig. 8). A blood count showed: Hb $92 \%$, R.B.C. $4,600,000$, W.B.C. 33,000 (eosinophils 61\%), E.S.R. 41.

Although treated on a sanatorium regime, no improvement in the severity of the illness or frequency of the asthmatic attacks could be achieved.

Widespread joint pains, particularly affecting the knees, shoulders, wrists, and fingers, and crops of red spots on the skin of the face, chest, and fingers developed later, in addition to the bowel and chest symptoms. A diagnosis of polyarteritis nodosa was made on clinical grounds.

Subsequently she went to Oxford, and after a period of observation at the Radcliffe Infirmary under the late Sir Arthur Hurst and Professor Witts, a course of N.A.B. was tried, which produced some benefit and a drop in the eosinophil count. No evidence of gastro-intestinal infestation could be found. Although the diarrhoea improved somewhat following the course of N.A.B., the asthmatic attacks persisted. In subsequent years she was found to be sensitive to most house dusts, but desensitization was never accomplished.

The last radiograph showed resolution of the miliary pattern in the right upper zone (Fig. 9).

CASE 7.-A housewife and part-time factory hand, aged 47 , had as first symptoms attacks of " asthma" in increasing frequency, which responded to ephedrine and adrenaline at first. Two years following the onset of these attacks she lost some 6 stones in weight, and began to experience paraesthesia, and later numbness in her hands and feet. Her stools became loose, containing blood and mucus, but there was no colic or tenesmus.

She was admitted under the care of one of us (P.E.). The chest expansion at first was good, the lung fields were hyper-resonant, movements at the bases were diminished, and coarse rales were audible at the bases.

A chest radiograph revealed a miliary or fine nodular infiltration of the upper zones. The leucocyte count was 27,000 per c.mm. with $54 \%$ eosinophils.
No pathogens were found in the faeces. Biopsy of a pectoral muscle was normal.

In the central nervous system there was evidence of hypoalgesia of all fingers with weakness of the muscles of the hand and forearm. The anterior tibial and the $\bar{c}$ peroneal muscles were weak and wasted. Posterior column proprioception was impaired in toe and ankle joints.

Although the muscle biopsy was negative this $\overrightarrow{0}$ patient was regarded as having polyarteritis nodosa with an eosinophilic lung infiltration, and she was $\vec{\omega}$ treated with a course of neoarsphenamine. The response to this was disappointing and she went down- $\overrightarrow{\vec{x}}$ hill rapidly, developing a right knee effusion, a left Horner's syndrome, and finally succumbed to rapid congestive heart failure.

The post-mortem examination showed widespread myocardial fibrosis and patchy consolidation through- $\frac{}{J}$ out both lungs. The blood vessels in the lungs showed only simple intimal thickening.

\section{RESPIRATORY MANIFESTATIONS ASSO- CIATED WITH RHEUMATOID DISEASE}

The last three patients in this series suffered from rheumatoid disease for some years before the onset of respiratory symptoms, which differed in their clinical course and severity.

\section{Clinical Course}

CASE 8.-A retired jeweller, aged 63, had a history of rheumatoid disease for 17 years, with the principal $\overline{\bar{\sigma}}$ arthritic manifestations in the knees, wrists, and 3 ankles. In the last seven years of his illness exacerbations of joint swellings were ushered in by cough, dyspnoea, and purulent sputum. While these attacks of "bronchitis" lasted his joints were always swollen 음 and painful, and remissions with a fall in the E.S.R. occurred as the chest symptoms subsided. In the eighteenth year of his disease he was admitted under 3 the care of one of us (P.E.) on account of increasing dyspnoea, loss of weight, swollen and painful joints, crops of nodules, and a painful left eye.

On examination the patient appeared very wasted 윽 and pale. He was dyspnoeic at rest. The left eye $D$ showed a patch of episcleritis on the lateral corneal scleral margin with a raised phlycten in the centre.

Painful nodules, the size of cherries, covered the $O$ back of his head, the left olecranon process, the ulnar $N$ borders of both forearms, and the ischial tuberosities. N The wrist and the metacarpo-phalangeal and knee $\omega$ joints were very swollen.

The heart was enlarged, with the apex beat $4 \frac{1}{2}$ in.e from the mid-sternal line. The sounds were normal. and the blood pressure was $105 / 65 \mathrm{~mm}$. Hg. The \& pulse rate was 45 , and an electrocardiogram showed $\square$ 2:1 heart block, with right axis deviation.

In the lung fields there were dullness and no air $\mathbb{D}$ entry at the left base, and bilateral rales.

Radiography of the chest confirmed the cardiac $\stackrel{\mathbb{D}}{\varrho}$ enlargement, and cardioscopy showed this to be due to right ventricular hypertrophy. There was an effu- $\Omega$ 


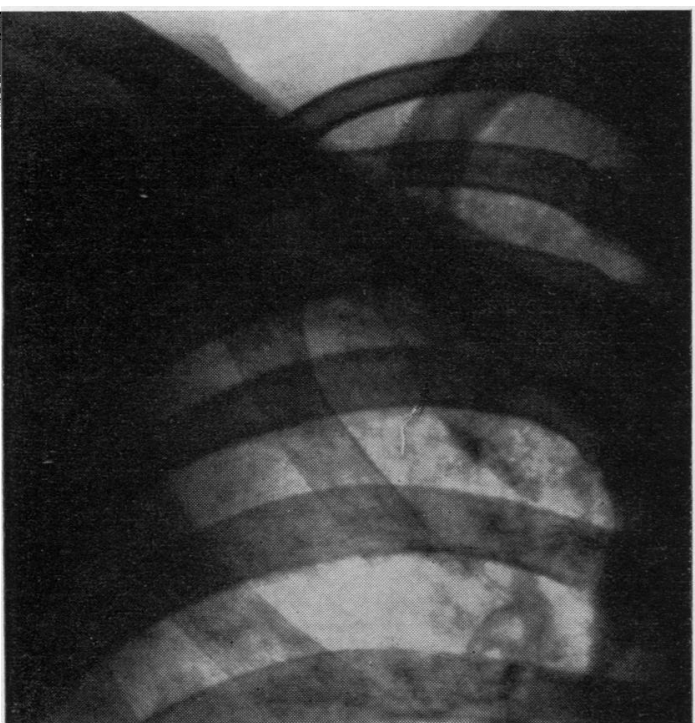

FIG. 8.-Case 6: polyarteritis nodosa. Right upper zone-showing an almost miliary pattern.

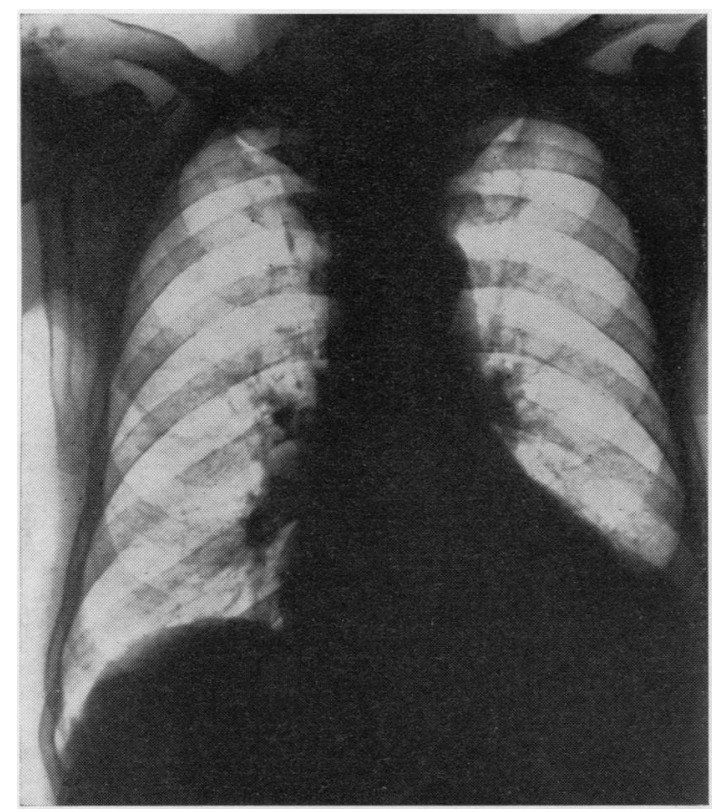

Fig. 10.-Case 8: rheumatoid disease with widespread rheumatic nodules. Postero-anterior radiograph of chest after prolonged cortisone therapy, showing persistence of left pleural effusion.

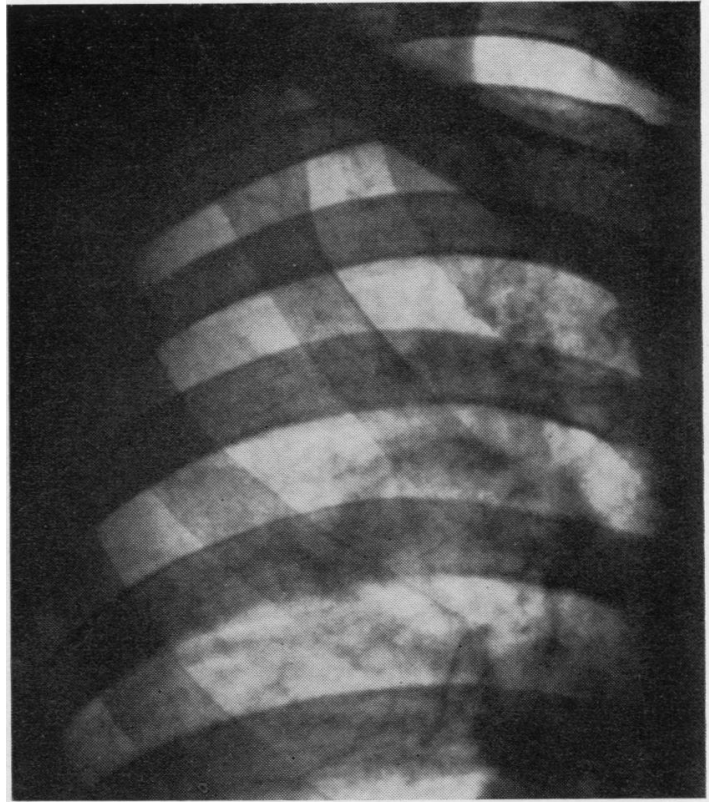

FiG. 9.-Case 6: polyarteritis nodosa. Right upper zone four years later, showing resolution of miliary pattern.

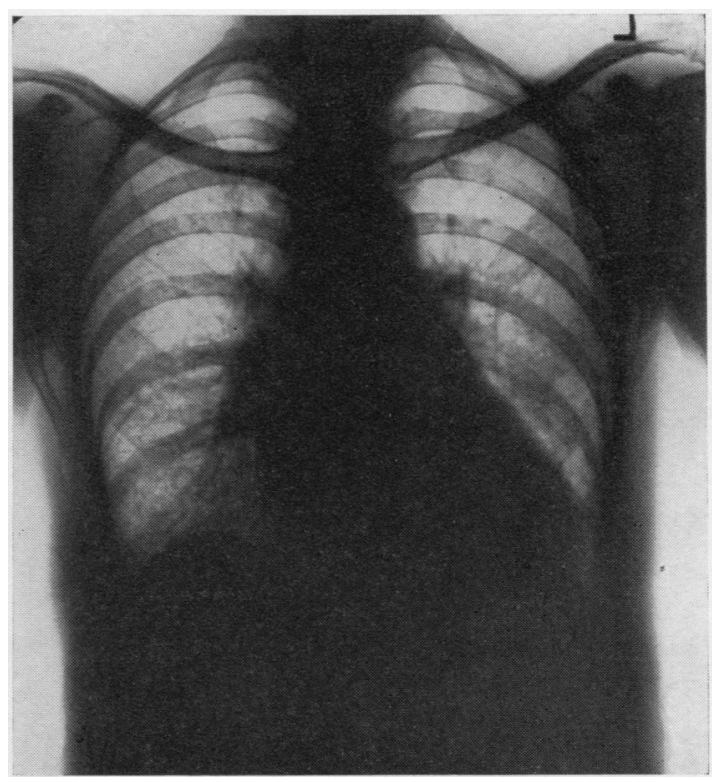

FIG. 11.-Case 9: rheumatoid arthritis. Postero-anterior radiograph of chest showing right para-cardiac shadow with increased basal reticulation. 
sion at the left base (Fig. 10). Aspiration of fluid from the left base showed a transudate. No malignant cells were seen, and cultures were sterile. A guinea-pig inoculation remained negative. Nothing abnormal was found in the urine, and renal function was normal. The E.S.R. fluctuated throughout his stay between 80 and $100 \mathrm{~mm}$.

After a period of observation he was given digitalis and also "mersalyl" twice weekly. This had no effect on the pleural effusion and the adventitious sounds.

Accordingly he was given cortisone for 71 days, starting with $100 \mathrm{mg}$. per day. On this regime the joint swellings and nodules regressed and the dyspnoea became less distressing. The effusion remained uninfluenced. There was no change in serum electrolytes, and at no time was oedema or a rise in jugular venous pressure noted.

Four months after cortisone was stopped the physical and radiological signs were unchanged.

CASE 9.-A housewife, aged 50, in the six years preceding an acute chest illness, had episodes of joint pains and swellings, leaving a limited range of movement, with stiffness at both wrists, prominence of the metacarpo-phalangeal joints, with early ulnar deviation of both fingers. The leit knee could not be fully extended.

She was admitted to hospital with a pyrexia of $104^{\circ} \mathrm{F}$., dyspnoea, and joint pains, without obvious

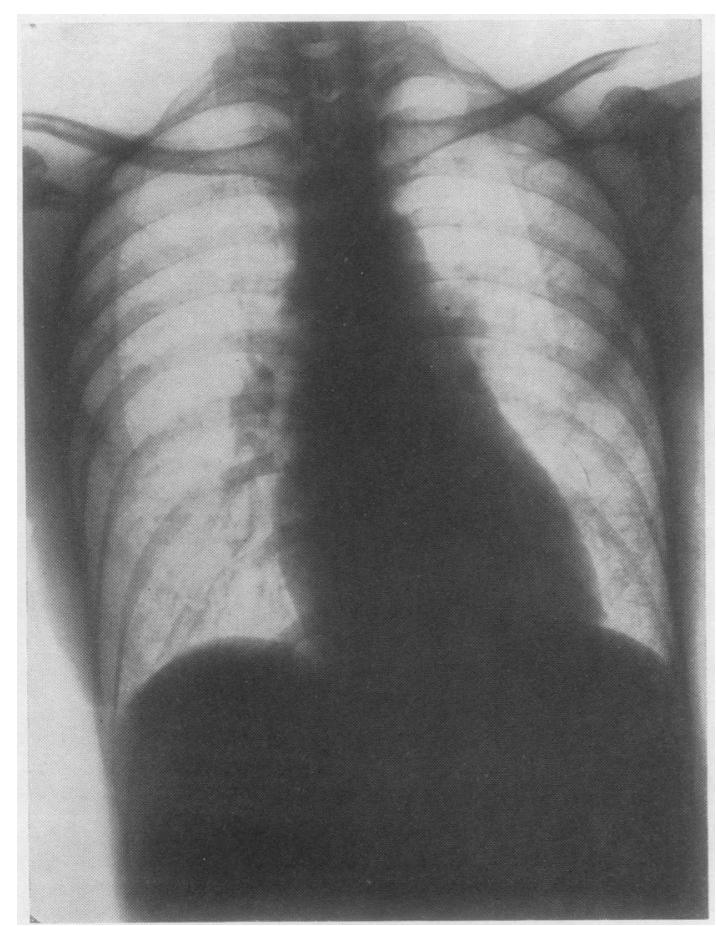

FIG. 12.-Case 9: the same, showing resolution in seventh mont of illness. swellings. The only abnormalities outside the locomotor system were crepitations at the bases of both lungs.

A chest radiograph showed a right paracardiac shadow with increased basal reticulation (Fig. 11). The E.S.R. was $11 \mathrm{~mm}$. A white blood count showed a polymorphonuclear leucocytosis of 13,000 per c.mm. All blood cultures and agglutination reactions were negative. A search for tubercle bacilli and all other tests were negative, and the pyrexia did not respond to chemotherapy.

In the second month of the illness a course of salicylates was started, which at first controlled the pyrexia rapidly. At the end of the second month the temperature climbed again and the E.S.R. was $52 \mathrm{~mm}$. White blood cells were 6,000 per c.mm. with a normal differential count.

A chest radiograph showed no change in the right basal shadow. The cardiovascular system appeared normal.

In the fourth month the E.S.R. had climbed to $86 \mathrm{~mm}$. and the patient began to improve. The pyrexia settled slowly and the shadow at the right base, as well as the basal reticulation, resolved, leaving no abnormal signs at the time of her discharge at the beginning of the seventh month of the illness (Fig. 12).

CASE 10.-A housewife, aged 58, developed bilateral pleural effusions in the sixth year of her illness. This was ushered in with widespread arthralgia, loss of weight, and high swinging fever. With the establishment of the effusion the wrists and the metacarpophalangeal and proximal phalangeal joints became swollen, and she also developed severe left episcleritis. The episcleritis and the effusions gradually subsided and she is now left with bilateral basal pleural fibrosis, and a typical rheumatoid arthritic lesion.

\section{DISCUSSION}

The respiratory manifestations in these 10 cases seemed to present rather different clinical and $\delta$ radiographic patterns in the four diagnostic groups. In the three cases of scleroderma, pro- $\frac{\text { ? }}{9}$ gressive dyspnoea developed late in the course of $\supset$ the disease, with radiographic changes at the bases of the lungs in two cases, and an enlarged pulmonary artery and evidence of pleural fibrosis in the other: the course was unaffected by treat- $N$ ment. In the two cases of disseminated lupus $\underset{\omega}{N}$ erythematosus, dyspnoea developed at the beginning of the disease with basal shadows in the 0 radiographs; the course was remittent, but irre. versible lung changes developed and were un- $\stackrel{\infty}{+}$ influenced by treatment. In the two cases of poly- 7 arteritis nodosa, asthma was the presenting respiratory symptom, and radiographically a fine $\stackrel{\mathbb{D}}{\stackrel{D}{\circ}}$ mottling was seen in both upper zones in one case $\stackrel{\mathbb{Q}}{\varrho}$ and in the right only in the other; dyspnoea was progressive, and one of the patients died from

,


pulmonary heart disease. Of the three cases of rheumatoid disease, one had unilateral and another bilateral pleural effusions, and the other an acute febrile illness with dyspnoea and a right paracardiac shadow; the lung changes were unaffected by treatment.

Cortisone, although life-saving in Case 4, certainly had no effect on the clinical and radiographic signs seen before or subsequently. It is our belief, therefore, that these lung changes were progressive in nine patients and self-limiting in the tenth case.

\section{The Literature in Relation to Pulmonary SCLERODERMA}

Finlay (1891) recognized the association between pulmonary fibrosis and generalized scleroderma. Matsui (1924) described three patients with pulmonary fibrosis and scleroderma in whom the total pulmonary artery bed was reduced, and the right ventricle enlarged. Kraus (1924), in a histological study of sclerodermatous lungs, observed some pulmonary emphysema with right ventricular hypertrophy. The alveolar septa were increased in width and "arteries" showed marked intimal proliferation. Their tunicae mediae were infiltrated with round cells. The first report of radiographic changes in sclerodermatous lungs was made by Murphy and others (1941), who recognized fibrosis spreading from the hila. Bronchography was normal. Linenthal and Talkov (1941) and Wigley and others (1949) also described cases of scleroderma in which pulmonary fibrosis preceded skin lesions. Weiss, Stead, Warren, and Bailey (1943) found mottling of the lungs in six out of nine cases. At necropsy alveolar fibrosis with reduction in calibre of the bronchi and pulmonary arteries was seen. They also described myocardial involvement.

Getzowa (1945) gave a more detailed pathological account of the lung lesions in scleroderma and described diffuse fibrosis of the alveolar wall with thickening, leading to obliteration of capillaries and alveolar spaces. Large coalescing islets of compact fibrous tissue alternated with areas of hyaline degeneration of the alveolar walls. The latter were sometimes thinned and ruptured, causing cyst formation under the visceral pleura. Getzowa believed that the collagen change precedes the obliterative vascular changes. Goetz (1945) emphasized the interstitial nature of the pulmonary fibrosis, and also referred to vascular narrowing. Baehr and Pollack (1947) regarded the primary abnormality in scleroderma as an endarteritis, with fibrinoid necrosis of the vessel walls and of the surrounding collagen tissue. Macroscopically, sclerodermatous lungs were found to be firm, inelastic and reduced in size. Dostrovsky (1947) described "pulmo-sclerosis cystica" with scleroderma occurring later in the disease. Pagel, Woolf, and Asher (1949) did not think that the lung pathology was specific. Lloyd and Tonkin (1948) described the clinical sequence in scleroderma lung disease as exertional dyspnoea, dry cough, and reduction in vital capacity. Radiologically this was associated with diffuse fibrosis. Church and Ellis (1950) referred to fibrocystic changes in the lungs, and found bronchiectasis in one case, and migrating lobar consolidation, not responding to chemotherapy, in another. They regarded the fibrosis as the result of pulmonary endarteritis. McMichael (1948) mentioned a case of widespread scleroderma with diffuse fibrosis, particularly accentuated at the right apex. In the last five years of the patient's illness dyspnoea became crippling, and the electrocardiogram showed right ventricular hypertrophy. Spain and Thomas (1950) recognized radiologically cystic lesions and extensive fibrosis of the basal pleurae. They thought that dyspnoea was due to impairment of gas exchange at the level of the alveoli, as no evidence of ventilatory insufficiency could be found. They noted fibrous replacement in the musculature of smaller bronchi, and referred to Bevans (1945), who noted marked narrowing of "pulmonary" vessels near these bronchi, notably in the smaller arteries.

The literature, therefore, recognizes diffuse pulmonary fibrosis, fine nodulation and cyst formation, as well as pleural fibrosis as the main abnormality in this disease. Bullous emphysema has not been described, and according to Baehr and Pollack (1947) the lungs, if anything, were smaller than normal. Interstitial thickening of the alveolar basement membranes is repeatedly emphasized. Although Church and Ellis (1950) referred to true bronchiectasis in one of their cases, dilatation of the bronchi does not appear to have been emphasized elsewhere, and it was not found in the bronchogram carried out in Case 1. The major clinical symptom in the patients recorded was progressive dyspnoea.

The Literature of Lung Changes in Dis-

Multiple opacities in the lungs of patients with disseminated lupus erythematosus were noted by Tumulty and Harvey (1949). Baggenstoss (1952) believed that no pathognomonic lesions had been described in the lungs, although clinically pulmonary involvement was remarkable for its frequency and atypical course. Rakov and Taylor (1942) described a chronic interstitial pneumonitis leading to atelectasis and respiratory 
failure. They found basophilic mucinous oedema of the alveolar walls, peribronchial and perivascular tissues, and alveolar haemorrhages. Baggenstoss believed that these interstitial lesions might be of considerable significance in clarifying atypical pulmonary symptoms in some cases of disseminated lupus. Robertson (1952), in a review of 58 cases of pleural effusion in adults over 40 , found that four suffered from collagen diseases, and in one necropsy identified this as disseminated lupus erythematosus.

The acute symptoms at the onset of the disease in Cases 4 and 5 of this series are perhaps a little unusual, but the subsequent course, and in particular the exacerbation of similar illnesses later in the course of the disease, as in Case 4, adds support to the view that the lung lesions are clearly part of the progressive disease process. The subsequent changes in the lungs were permanent.

The Literature of Polyarteritis Nodosa and Lung Changes

This disease was first described by Kussmaul and Maier (1866). In discussing the pathology Miller (1949) spoke of necrotizing panarteritis with fibrinoid necrosis affecting all coats, and emphasized the fact that eosinophilia seems common only in patients who have asthma. Harkavy (1943) demonstrated vascular lesions in the lungs of asthmatics. Bergstrand (1946) referred to the resemblance of the vessels in asthmatic lungs to those in polyarteritis nodosa. Migrating opacities in the lungs of patients with polyarteritis nodosa have been noted by Weir (1939), Elkeles (1944), and Miller and Daley (1946).

\section{The Literature of Lung Changes IN Rheumatold Disease}

"Rheumatic pneumonias" have long been recognized in relation to rheumatic fever. Cheadle (1888), Naish (1928), Rabinowitz (1926), Muirhead and Haley (1947), and van Wijk (1948) spoke of lower lobe consolidation of variable duration. Paul (1928), Neubuerger, Geever, and Rutledge (1944) and Jensen (1946) refer to multilobar involvement. Von Glahn and Pappenheimer (1926) found arteritis in $20 \%$ of rheumatic fever lungs with concentric thickening of vessels, and revascularization of the intima. Masson and others (1937) described an alveolar fibrin coagulum and widened alveolar ducts lined by an eosinophilic membrane. Gouley (1938) thought that chronic diffuse fibrosis was a sequel to the lung involvement in rheumatic fever.

Changes resembling those seen in rheumatic "pneumonia" were produced experimentally by Gregory and Rich (1946), who considered that an anaphylactic angiitis affected the pulmonary capillaries. While lung changes in rheumatic fever are well known, the association of lung changes with rheumatoid arthritis has only recently been appreciated (Ellman, 1947; Ellman and Ball, 1948 ; Hart, 1948 ; Leys and Swift, 1949 ; Schlesinger, 1949; and Lees, 1952). The radiographic picture varied from basal consolidation to widespread bilateral reticulation. Ellman and Ball (1948) recorded interalveolar exudation with collapse of alveoli and thickening of the interalveolar septa in two of their cases at necropsy.

Case 8 in the present series was perhaps unusual in that pleural involvement alone was suspected. के Baggenstoss and Rosenberg (1943) and Raven, 0 Weber, and Price (1948) have, however, recorded instances of pleural nodulation associated with $\bar{z}$ necrobiotic nodules elsewhere. In Case 9 there was basal consolidation, which remained un- $\mathcal{S}$ influenced by chemotherapy, and ultimately resolved leaving no disability.

Rich, in the 1946-47 Harvey Lectures, emphasized the overlap between the systemic collagen diseases, rendering the differential diagnosis not only difficult but often impossible. Miller (1949) believed that the vascular changes were essential to all these disorders, producing clinical features as variable as the Henoch-Schoenlein type of allergy at one end of the scale, and chronic polyarteritis nodosa at the other. While the vascular pathology is well established the curious specificity of lesions in certain tissues remains un- $\vec{\partial}$ explained. The vascular changes which have been described in the lungs in all these diseases is of $:$ interest, in that the vessels involved need still to be 3 . properly identified. Matsui (1924), Weiss and $\delta$ others (1943), Bevans (1945), and Church and Ellis (1950) considered that the vascular changes in 0 scleroderma were in the pulmonary artery. In the same disease Kraus (1924) referred only to intimal proliferation in "small arteries" near the alveolar septa. Goetz (1945) spoke of "vascular" narrow- $/$ ) ing. Von Glahn and Pappenheimer (1926) N observed concentric thickening of "vessels" and N revascularization of the intima in rheumatic pneu- $\sigma$ monias. It appears, therefore, that the identity of these vessels is by no means clear. In ordinary lung sections it is nearly impossible to distinguish between bronchial or pulmonary arterioles, unless one of these circulations has been previously in- 0 jected with a contrast medium too coarse to $\mathbb{D}$ traverse the capillary beds. Using such a medium $\frac{\odot}{\mathbb{D}}$ it is possible to inject the bronchial circulation and study the intra-pulmonary distribution of the bronchial arteries (Cudkowicz and Armstrong, $\overparen{O}$ 1951). In normal lungs the bronchial arteries? 
supply all pulmonary supporting structures, the bronchial tree, interalveolar septa, visceral pleura, all intra-pulmonary nerves and plexuses, the lymph nodes at the hila, and furnish the vasa vasorum to the pulmonary arteries.

The pulmonary lesions of the systemic collagen diseases appear to be confined to the pleura, the inter-lobular septa and the alveolar-supporting membranes, the smaller bronchi and peribronchial tissues and, as in Case 2, to the walls of the pulmonary artery. This suggests that the wide, diffuse changes seen throughout both lung fields (at least in scleroderma) are in the exclusive territory of the bronchial arteries, and that the lesions recorded by Bevans (1945) in the wall of small bronchi affected occluded bronchial arteries. Total occlusion of the bronchial arteries would deprive the lungs and the visceral pleura of their only arterial blood supply at least until such time as it takes for pleural adhesions to form, and to convey new parietal pleural arteries into the occluded bronchial artery bed. This is seen in pulmonary tuberculosis (Cudkowicz, 1952). Miller (1949) believed that a panarteritis underlies the manifestations of collagen disease. The lung lesions in these diseases, because of their characteristic pathological localization, suggest involvement of the bronchial circulation in its wide distribution. As this circulation is responsible for the nutrition of all lung structures except the respiratory epithelium of the alveolar capillaries, it is reasonable to suppose that the variable degrees of pulmonary sclerosis seen in scleroderma and disseminated lupus have resulted from the deprivation of the only arterial blood supply available to the supporting structures of the lungs.

\section{SUMMARY}

The clinical and radiographical features of lung involvement in 10 patients suffering from the systemic collagen diseases have been described. The response of these lesions to treatment, including hormonal therapy, was very disappointing, and in only one instance was the lung disease selflimiting.

The literature in respect of the pulmonary manifestations has been reviewed. Histologically, variable degrees of vascular occlusion have been found, probably in the territory of the bronchial arteries. The lung changes in this disease group may represent the effects of progressive pulmonary ischaemia resulting from the loss of a bronchial arterial blood supply.

We are indebted to Professor J. McMichael for his help in Case 2, to Professor L. J. Witts in Case 6, and to Dr. A. Wingfield and Mr. W. P. Cleland respec- tively for referring Cases 4 and 5 to one of us. Finally, we should like to express our indebtedness to Professors Sir Henry Cohen and Alan Kekwick for having so carefully perused the manuscript, and to Mr. K. Moreman, A.R.P.S., for his reproduction of the radiographs.

\section{REFERENCES}

Baehr, G., and Pollack, A. D. (1947). J. Amer. med. Ass., 134, 1169 Baggenstoss, A. H. (1952). Proc. Mayo Clin., 27, 412. and Rosenberg, E. F. (1943). Arch. Path. Chicago, 35, 503. Bahrmann, E. (1935). Virchows Arch. path. Anat., 296, 277.

Banks, B. M. (1941). New Engl. J. Med., 225, 433.

Bergstrand, H. (1946). J. Path. Bact., 58, 399.

Bevans, M. (1945). Amer. J. Path., 21, 25.

Bevans, M. (1945). Amer. J. Path., 21, 25.

Bywaters, E. G. L. (1949), Ann. rheum.
Cheadle, W. B. (1888). Lancet, 1, 861.

Cheadle, W. B. (1888). Lancet, 1, 861. I I I id., 1, 392

Cudkowicz, L. (1952). Thorax, 7, 270.

and Armstrong, J. B. (1951). Ibid., 6, 343.

Dostrovsky, A. (1947). Arch. Derm. Syph., Chicago, 55, 1.

Elkeles, A. (1944). Brit. J. Radiol., 17, 368.

Ellman, P. (1947). Proc. roy. Soc. Med., 40, 332.

Ellman, P. (1947). Proc. roy. Soc. Med., 40, 332.

Finlay, D. W.'(1891). Middx. Hosp. Rep., 29.

Getzowa, S. (1945). Arch. Path. Chicago, 40, 99.

Glahn, W. C. von, and Pappenheimer, A. M. (1926). Amer. J. Path., 2, 235.

Goetz, R.' H. (1945). Clin. Proc., Cape Town, 4, 337.

Gouley, B. A. (1938). Amer. J. med. Sci., 196, 1.

Gregory, J. E., and Rich, A. R. (1946). Bull. Johns Hopk. Hosp., $78,1$.

Hadfield, G. (1938). Lancet, 2, 710

Harkavy, J. (1941). Arch. intern. Med., 67, 709.

(1943). J. Allergy, 14, 507.

Hart, F. D. (1948). Brit. med. J., 2, 996.

Hayman, L. D., and Hunt, R. E. (1952). Dis. Chest, 21, 691.

Jackman J (1943) Radiology, 40,163.

Jensen, C. R. (1946). Arch. intern. Med., 77, 237.

Kampmeier, R. H. (1950). Amer. Practit. Philad., 1, 113

Kampmeier, R. H. (1950). Amer. Practit. Philad.,

Klemperer, P. (1948). Ann. intern. Med., 28, 1.

- Pollack, A. D., and Baehr, G. (1942). J. Amer. med. Ass., 119, 331.

Kraus, E. J. (1924). Virchows Arch. path. Anat., 253, 710.

Kussmaul, A., and Maier, R. (1866). Dtsch. Arch. klin. Med., 1, 484.

Lees, A. W. (1952). Brit. med. J., 1, 246.

Leys, D. G., and Swift, P. N. (1949). Ibid., 1, 434.

Linenthal, H., and Talkov, R. (1941). New Engl. J. Med., $224,682$.

Lloyd, W. E., and Tonkin, R. D. (1948). Thorax, 3, 241.

Masson, P., Riopelle, J. L., and Martin, P. (1937). Ann. Anat. path. méd.-chir., 14, 359.

Matsui, S. (1924). Mitt. med. Fak. Tokio, 31, 55.

McMichael, J. (1948). Edinb. med. J., 55, 65.

Miller, H. G. (1949). Proc. roy. Soc. Med., 42, 497.

and Daley, R. (1946). Quart. J. Med., 15, 255.

Muirhead, E. E., and Haley, A. E. (1947). Arch. intern. Med., 80, 328.

Murphy, R. J., Krainin, P., and Gerson, M. J. (1941). J. Amer. méd. Ass., 116, 499.

Naish, E. A. (1928). Lancet, 2, 10.

Neubuerger, K. T., Geever, E. F., and Rutledge, E. K. (1944). Arch. Path. Chicago, 37, 1.

Pagel, W., Woolf, A. L., and Asher, R. (1949). J. Path. Bact., 61, 403.

Paul, J. R. (1928). Medicine, 7, 383.

Platt, R. (1949). Proc. roy. Soc. Med., 42, 504

Rabinowitz, M. A. (1926). J. Amer. med. Ass., 87, 142

Rakov, H. L., and Taylor, J. S. (1942). Arch. intern. Med., 70, 88.

Raven, R. W., Weber, F. Parkes, and Price, L. W. (1948). Ann. rheum. Dis., 7, 63.

Rich, A. R. (1942). Bull. Johns Hopk. Hosp., 71, 123. (1946). Harvey Lect. 42, 106.

and Gregory, J. E. (1943), Bull. Johns Hopk. Hosp., 73, 239. Robertson, R. F. (1952). Brit. med. J., 1, 133.

Sante, I. R., and Wyatt, J. P. (1951). Amer. J. Roentgenol., 66, 527.

Schlesinger, B. (1949). Brit. med. J., 2, 197.

Spain, D. M., and Thomas, A. G. (1950). Ann. intern. Med., 32, 152.

Spühler, O., and Morandi, L. (1949). Helv. med. Acta, 16, 147.

Stokes, J. H., Beerman, H., and Ingraham, N. R. (1944). Amer. J. med. Sci., 207,540 .

Tumulty, P. A., and Harvey, A. M. (1949). Bull. Johns Hopk.

Hosp., 85, 47.

Weiss, S., Stead, E. A., Warren, J.' V., and Bailey, O. T. (1943). Arch. intern. Med., 71, 749.

Wigley, J. E. M., Edmunds, V., and Bradley, R. (1949). Brit. J. Derm., 61, 324.

Wijk, E. van (1948). Acta paediat., Uppsala, 35, 108 